\title{
Análise econômica da primeira Lei de Patentes brasileira
}

\author{
Andrea Felippe Cabello \\ Professora - Universidade de Brasília (UnB) \\ Endereço: Caixa Postal 4302 - Brasília/DF \\ CEP: 70919-970 - E-mail: andreafc@unb.br \\ Luciano Martins Costa Póvoa \\ Consultor Legislativo do Senado Federal - Senado Federal \\ Endereço: Praça dos Três Poderes - Brasília/DF \\ CEP: 70165-900 - E-mail: Ipovoa@senado.leg.br \\ Recebido: 15/12/2014. Aceite 16/03/2016.
}

\section{Resumo}

O Brasil foi um dos primeiros países a ter uma lei de patentes e um dos únicos a conceder prazos de duração da patente de acordo com a qualidade da invenção. Este trabalho analisa um banco de dados inédito com todos os 783 privilégios industriais concedidos sob a vigência da primeira lei de patentes brasileira entre 1830 e 1882. Os resultados mostram que a atividade inventiva esteve conectada à estrutura econômica e social da época e que a escassez de mão de obra incentivou a invenção de máquinas e equipamentos para o setor cafeicultor. O número de patentes apenas começou a se elevar a partir de 1870, quando a economia brasileira passou por grandes mudanças que levaram ao seu desenvolvimento, evidenciando que pouco resultado surge quando se institui uma lei de patentes em um ambiente de estagnação econômica. Mesmo assim, a lei revelou-se o mecanismo menos dispendioso para estimular a atividade inventiva no Brasil do século XIX.

\section{Palavras-Chave}

Lei de patentes. Invenções. Eficiência das leis.

\begin{abstract}
Brazil was one of the first countries to have a patent law and one of the only ones to grant patent length according to the quality of the invention. This paper analyzes an unpublished dataset with all the 783 industrial privileges granted under the first Brazilian patent law between 1830 and 1882 . Our results show that inventive activity was linked to the economic and social structure of the time and that labor scarcity led to the invention of machines and equipment for the coffee sector. The number of patents only increased from 1870 and on, when economic conditions improved, showing how little can be achieved by a patent law in an economically stagnant environment. However, it was the least expensive mechanism to stimulate inventive activity in Brazil in the XIX century.
\end{abstract}

\section{Keywords}

Patent law. Inventions. Law efficiency.

\section{JEL Classification}

N76

- Os autores agradecem os comentários e as sugestões de Luiz Ricardo Cavalcante e dos pareceristas anônimos desta revista. 


\section{Introdução}

Às vezes a história nos provê dados melhores do que a atualidade. Isso acontece, entre outros fatores, por causa de ambientes menos litigiosos no passado (GOLDIN, 1995). Assim, é possível estudar os efeitos de regras que dificilmente poderiam ser aplicadas nos tempos atuais, mas que proporcionam maior entendimento sobre as relações econômicas e sociais.

Esse é o caso quando tratamos de patentes. Dado que cada invenção possui um valor econômico potencial diferente, a teoria econômica indica que o bem-estar social seria maximizado com o estabelecimento de prazos distintos de duração do monopólio legal conferido pela patente. Entretanto, tal regra é praticamente impossível de ser aplicada, pois gera um custo de transação impeditivo. Além de ser difícil chegar a algum consenso sobre quais critérios utilizar para se determinar a duração de uma invenção, haveria sempre a possibilidade de terceiros contestarem judicialmente o prazo escolhido.

Por exemplo, atualmente, a maioria dos países adota um prazo fixo de vinte anos para a duração do monopólio, contado a partir da data de depósito do pedido de patente. Por isso, uma das principais limitações do uso de dados de patentes para estudar a taxa e a direção da atividade inventiva é que cada patente tem o mesmo prazo e conta como uma única invenção, independentemente da sua importância ou qualidade (GRILICHES, 1990). Portanto, existe uma variabilidade da importância econômica das invenções que não é capturada pelos dados de patentes.

No passado, alguns países definiram regras com diferentes prazos de acordo com cada patente. A lei de patentes dos Estados Unidos de 1790 estabelecia que os membros do Conselho de Patentes poderiam atribuir qualquer duração, desde que não excedesse catorze anos.

Uma disposição semelhante também foi incluída na primeira lei de patentes brasileira, promulgada em 1830 e que durou até 1882. De acordo com a lei, cada patente tinha seu prazo determinado pela qualidade da invenção, o que pode ser entendido como sua importância econômica ou valor social. A lei também concedia patentes para melhorias e definia um prêmio para os estrangeiros que introduzissem suas invenções no país. 
Este trabalho analisa os efeitos dessas regras normativas sobre a eficiência da primeira lei de patentes brasileira. Para tanto, seguimos a proposição de Stigler (1991), segundo o qual a eficiência de uma lei deve ser julgada apenas em relação aos seus objetivos. Assim, a lei de patentes é dita eficiente se não tiver existido outra forma menos dispendiosa de incentivo à geração de invenções no Brasil do século XIX.

A análise é feita com base em um banco de dados histórico inédito com todos os 783 privilégios industriais concedidos sob a vigência da primeira lei de patentes do Brasil. A classificação dessas patentes possibilitou determinar os tipos de invenções que surgiram e quais foram as mais "valorizadas" em uma economia essencialmente agrícola do século XIX, baseada em exportações de café.

A próxima seção apresenta os argumentos teóricos sobre a eficiência das patentes e questiona seu papel no incentivo às invenções. A terceira seção descreve os objetivos e as principais características da lei de patentes brasileira de 1830. A base de dados é apresentada na quarta seção, bem como sua singularidade e limitações. A quinta seção é dedicada à análise da conexão das patentes com a estrutura produtiva brasileira, as características da lei de patentes e a questão das patentes de estrangeiros de forma a avaliar a eficiência da lei. As conclusões são apresentadas na última seção.

\section{Direito de propriedade industrial incentiva o surgimento de invenções?}

Segundo o argumento econômico tradicional, o direito de propriedade industrial, em especial a patente de invenção, incentiva a oferta de invenções na sociedade e, consequentemente, o desenvolvimento econômico (MAZZOLENI e NELSON, 1998). Por meio da patente, o Estado concede e garante um direito de propriedade exclusivo temporário aos inventores, o que lhes permite exercer poder de monopólio e obter retorno econômico. Como contrapartida, exige-se a divulgação dos detalhes da invenção como meio de disseminação do conhecimento. Esse incentivo ao engajamento em mais atividades inventivas é chamado de "eficiência dinâmica" do sistema de pa- 
tentes. ${ }^{l}$ Por outro lado, a patente confere ao inventor um poder de monopólio, pois apenas ele pode definir quem faz uso econômico da invenção, o que gera a chamada ineficiência estática das patentes.

A eficiência geral de uma lei de patentes depende de sua aplicação e da forma como é estabelecida a propriedade industrial. ${ }^{2}$ Em primeiro lugar, a propriedade deve ser garantida pelo Estado. Caso não existam mecanismos efetivos para punir os infratores, a patente não servirá de estímulo ao investimento em atividades inventivas. Em segundo lugar, a invenção é um bem intangível e a definição de sua propriedade é complexa. Ao contrário de um bem imóvel, cuja propriedade pode ser definida em termos geográficos, a propriedade de uma invenção é difícil de ser definida. Por ter características de bem rival, a invenção pode ser usada por mais de uma pessoa ao mesmo tempo sem ter sua utilidade diminuída, o que dificulta sobremaneira o exercício da propriedade exclusiva.

A literatura econômica tem se concentrado no dilema entre a eficiência dinâmica (a patente serve de incentivo ao surgimento de novas invenções) e a ineficiência estática (gerada pelo poder de monopólio que a patente permite exercer). Os inventores devem ter seus inventos protegidos pela patente, mas, se o grau de proteção for muito elevado, pode haver uma redução do surgimento de novas invenções. A maior parte dos estudos argumenta que o grau de proteção é dado pela combinação entre a duração e a abrangência da patente. Essas duas dimensões ajudam a definir a propriedade da invenção e a forma como a lei de patentes as define afeta a sua eficiência no sentido de incentivar o surgimento de mais invenções. ${ }^{3}$

Em um trabalho seminal, Nordhaus (1969) utilizou a teoria econômica para analisar a duração ótima das patentes, considerando que a duração afeta os investimentos em pesquisa e desenvolvimento $(\mathrm{P} \& \mathrm{D})$. Se a lei de patentes define um período curto de proteção, os

1 Consideramos "sistema de patente" todo o conjunto de instituições que contribuem para a efetividade da garantia da propriedade industrial. Assim, a lei de patentes de um país é um dos componentes do seu sistema de patentes. Um judiciário que garanta esse direito também faz parte do sistema de patentes.

2 A eficiência de uma lei de patentes também depende de uma série de instituições complementares, tais como o sistema financeiro e o educacional. Este artigo se concentra na análise dos fatores internos à lei, como a duração da patente.

3 Alguns estudos analisam uma terceira dimensão patente chamada de "altura" das patentes, que se refere à proteção que uma patente pode conferir quanto às melhorias (ver LANGINIER e MOSCHINI, 2002). 
inventores irão dedicar menos esforços em P\&D. Por outro lado, um período muito longo irá reduzir os benefícios futuros para os consumidores após a expiração da patente. $\mathrm{O}$ modelo algébrico elaborado pelo autor permite concluir que a duração de uma patente depende da elasticidade da demanda, da importância da invenção e da curva de possibilidade de invenção. Quanto mais importante uma invenção, menor deve ser a duração da patente para que a sociedade como um todo possa usufruir o quanto antes de seus benefícios, reduzindo assim a chamada perda de peso morto causada pelo monopólio temporário. Esse resultado de Nordhaus (1969) contraria o senso comum de que invenções mais importantes devem ter duração mais longa. Contudo, invenções drásticas de processo, ou seja, aquelas que tendem a cortar custos e a reduzir a perda de peso morto causada pelo monopólio, deveriam ter duração longa. Assim, a duração ótima de uma patente depende do tipo de invenção.

Scherer (1972) baseia-se no trabalho de Nordhaus (1969) e, além de chegar a resultados opostos utilizando a mesma base teórica, conclui que um sistema ideal de patentes estabeleceria a duração de cada patente com base nas características econômicas de cada invenção. Nordhaus (1972), em uma réplica a Scherer (1972), deixa claro que as conclusões de ambos são sensíveis às hipóteses do modelo, que considera apenas a situação inicial de concorrência perfeita e ausência de incerteza. Contudo, ambos autores concordam que um sistema de patentes com um prazo único para todas as invenções é ineficiente.

Diversos trabalhos ampliaram o debate sobre o sistema ideal de patentes ao introduzir a o aspecto da abrangência, ou seja, o quão diferente deve ser uma nova invenção para que não viole uma patente existente. Uma patente de abrangência estreita confere um direito de propriedade mais restrito ao inventor, permitindo o surgimento de produtos similares e maior competição, o que beneficia os consumidores. Por outro lado, uma patente de abrangência ampla proporciona ao inventor um poder de monopólio elevado pois impede o surgimento de produtos similares, o chamado processo de inventing around. Stiglitz (2008, p. 1702-03) cita o exemplo da patente norte -americana para o automóvel de 1895 (U.S. Patent no 549,160), que foi concedida de forma bastante ampla: 
In the case of the automobile, a patent was granted, but it was an excessively generic patent for a four-wheeled, self-propelled vehicle. The person who received the patent had no intention of developing the automobile; instead, he used it to form a cartel. Often, the best, or at least the easiest, way of making money is not to come up with a better idea but to form a monopoly or a cartel and restrict competition. For those seeking easy profits, competitive marketplaces are very bad because they drive down prices and erase profits. [Intellectual property rights] IPR can be an important way of maintaining a cartel. Most of the automobile companies went along with the idea of the patent driven cartel, except for one. There was one innovator who had a different conception of what the automobile was about, and that was Henry Ford. He had the idea of a people's car, at a low price; that idea was totally inconsistent with the cartel's view of a high-priced, restricted-use vehicle. Ford challenged the patent. Had he not had the resources and the determination, he would not have succeeded in this legal battle; however, he eventually did prevail. Had he failed, the development of the automobile as we know it would have been delayed for a long time.

Assim, o debate passou a questionar a combinação ideal entre duração e abrangência para estimular o surgimento de invenções. Em geral, os estudos discutem o tradeoff entre a necessidade de recompensar os inventores e a perda de bem-estar imposta à sociedade pelo poder de mercado criado pela proteção da propriedade intelectual. Os estudos mais influentes a respeito desse tema tiveram seu auge na década de 1990 (GILBERT e SHAPIRO, 1990; KLEMPERER, 1990; GALINI 1992; DENICOLÒ, 1996; O'DONOGHUE et al., 1998), mas ainda não há consenso na literatura a respeito de qual seria a melhor combinação. 
Gilbert e Shapiro (1990) argumentam que patentes deveriam ter duração infinita com abrangência variável de forma a permitir o menor poder de monopólio possível para um dado fluxo de lucros. ${ }^{4}$ Klemperer (1990) argumenta que o melhor sistema depende da disposição dos consumidores em usar produtos substitutos, podendo a combinação ótima ser de patentes amplas e de curta duração (substituição difícil entre produtos) ou patentes estreitas e de duração infinita (substituição fácil). Em ambos os casos, a perda de peso morto causada pelo monopólio é minimizada. O trabalho de Gallini (1992) parte da premissa de que se os custos de imitar um produto patenteado são elevados, a combinação ótima seria patentes amplas, que dificultariam a imitação e induziriam a inovação, com duração curta.

Denicolo (1996) reconhece que esses estudos são extremamente dependentes de como se define abrangência e das hipóteses adotadas (produto homogêneo - GILBERT e SHAPIRO, 1990; diferenciação de produtos do tipo custo de transporte - KLEMPERER, 1990; elevado custo de imitação - GALLINI, 1992). Assim, é natural que se tenha obtido resultados distintos. $\mathrm{O}$ autor tenta evitar a dependência de hipóteses restritivas e aborda a questão da competitividade do mercado, argumentando que se o grau de competição existente na economia é baixo, as patentes devem ser amplas, mas de curta duração.

O trabalho de O'Donoghue et al. (1998), apresenta a definição de "vida efetiva da patente", que é o prazo em que expira a patente ou quando uma outra invenção a suplanta sem infringi-la antes de vencer o seu prazo. Os autores elaboram o modelo mais realista entre os estudos citados e levam em consideração o fato de que as invenções são cumulativas. Em sua conclusão, apontam que se o objetivo da política de patentes for aumentar a difusão de novos produtos, as patentes devem ser finitas, mas bastante amplas.

Embora essa linha de pesquisa tenha arrefecido nos últimos anos sem chegar a um consenso, podem ser tiradas algumas conclusões importantes. Em primeiro lugar, os estudos sugerem a possibilidade de duas combinações candidatas a ideais para estimular as invenções sem conferir um poder de monopólio demasiadamente elevado: (i)

${ }^{4}$ Os mesmos autores argumentam que se a perda de bem-estar provocada pela patente for decrescente em relação à sua amplitude, patentes mais curtas, mas bastante amplas, poderiam ser o desenho ótimo, buscando-se atingir o mesmo fluxo de lucros, já que nesse caso seria possível reduzir a perda de peso morto com uma "largura" maior. 
patentes de longa duração e estreitas; e (ii) patentes de curta duração e amplas. A escolha da opção mais adequada depende das características do mercado, como o grau de competição. Em segundo lugar, uma duração única para todas as patentes é uma solução subótima, pois confere um incentivo demasiadamente elevado para invenções triviais. Por fim, a duração de uma patente é definida em lei, mas a sua abrangência é endógena, ou seja, depende das reinvindicações do inventor ao fazer o pedido de patente e da orientação geral do órgão examinador dos pedidos (LANGINIER e MOSCHINI, 2002).

Na última década surgiram estudos que passaram a questionar a necessidade de um sistema de patentes para estimular o surgimento de invenções. Boldrin e Levine (2013) apresentam uma revisão da literatura com vários argumentos de que não existem evidências empíricas de que patentes estimulam o aumento da inovação e da produtividade de um país no longo prazo. Os autores chegam a advogar pela eliminação das patentes pois mesmo um sistema de patentes bem elaborado, que poderia ser eficiente, sofre pressões dos agentes que se beneficiam do poder de monopólio que tornam as patentes danosas à sociedade.

A controvérsia sobre a real necessidade de uma lei de patentes para impulsionar a atividade inventiva não é recente. Machlup e Penrose (1950) relatam os descontentamentos com as patentes em diversos países europeus na segunda metade do século XIX. Em 1827, durante as discussões sobre a reforma do sistema de patentes da Inglaterra, ou seja, na época da elaboração da primeira lei de patentes brasileira, alguns grupos influentes da sociedade (grandes inventores, membros do parlamento e o editorial da revista Economist) passaram a advogar pela abolição do sistema de patentes. $\mathrm{Na}$ Alemanha, o movimento contra as patentes utilizou argumentos relacionados ao livre comércio e os economistas eram praticamente unânimes em condenar as patentes (MACHLUP e PENROSE, 1950, p. 5-6).

Mokyr (2009) retoma a controvérsia do século XIX, ao discutir a real contribuição das patentes para impulsionar a Revolução Industrial. $\mathrm{O}$ autor apresenta evidências empíricas que sugerem um papel mais modesto do que se supunha. Em primeiro lugar, muitos dos considerados grandes inventores da época eram contra as patentes. Em segundo lugar, com base nos estudos de Moser $(2005,2007)$ sobre aproximadamente 15 mil novas invenções apresentadas nas 
feiras internacionais de 1851, em Londres, e em 1876, na Filadélfia, pode-se chegar a um valor sobre o percentual das invenções que eram patenteadas. Como as feiras concentravam a "nata" das invenções, chega a ser surpreendente que apenas $11 \%$ das invenções apresentadas em Londres eram patenteadas e apenas $16 \%$ na Filadélfia. $^{5}$

Diante desses resultados, podemos questionar se realmente era necessário um sistema de patentes no Brasil ainda no século XIX. Griliches (1990) destaca que nem todas as invenções são patenteáveis e nem todas são patenteadas. Muitos inventores preferem manter o segredo industrial e aproveitar as vantagens de ser o primeiro (first mover). Contudo, muitas invenções relevantes estão em seu estágio inicial ou são fáceis de serem copiadas e poderiam ter seu desenvolvimento desestimulado na ausência de uma lei de patentes, prejudicando toda a sociedade. Para incentivar o surgimento dessas invenções, o Estado pode utilizar outros mecanismos como o estabelecimento de prêmios ou o financiamento à pesquisa básica.

Stiglitz (2008) argumenta que o sistema de prêmios possui vantagens sobre as patentes por causar menos distorções na economia. Os prêmios seriam concedidos àqueles que conseguissem desenvolver um produto ou serviço demandado pelo governo, como um medicamento para uma doença específica. A partir de então, a inovação seria disponibilizada para a sociedade, evitando as ineficiências geradas pelo monopólio concedido pelas patentes. Para o autor, o ideal seria contar com um porftfolio de mecanismos para incentivar a inovação, em que os direitos de propriedade industrial seriam um deles, junto com prêmios e financiamento a projetos de pesquisa.

Nas próximas seções argumentamos que a primeira lei de patentes brasileira apresentava uma combinação de mecanismos de incentivo à atividade inventiva, incluindo prêmios, e discutimos os efeitos de cada um deles.

5 Vale destacar que a institucionalização da $\mathrm{P} \& \mathrm{D}$ dentro das empresas somente ocorreu no final do século XIX, momento a partir do qual grandes empresas alemãs e norte-americanas passaram a ter uma atividade mais sistemática de desenvolvimento de produtos e processos com base em pesquisas aplicadas. 


\section{A Lei de patentes de 28 de agosto de 1830}

O Brasil foi um dos primeiros países a conceder patentes a inventores $^{6}$ e o único a ter uma lei de patentes antes de sua antiga metrópole. Mas, ao contrário das experiências de outros países, a primeira lei de patentes brasileira surgiu com o objetivo de incentivar o surgimento de invenções em vez de ser uma demanda dos inventores por proteção de seus ganhos.

A vinda da família real para o Brasil trouxe profundas mudanças para a colônia. Ao se transformar em centro das decisões políticas do reino de Portugal por treze anos, o Brasil passou a receber uma atenção inicial para se desenvolver economicamente. Entre as primeiras medidas que visavam o desenvolvimento da atividade industrial estavam a permissão de se instalarem fábricas no país (1808) e o Alvará de 28 de abril de 1809, cujo conteúdo tratava, entre outros assuntos, da questão do privilégio exclusivo por catorze anos aos "inventores e introdutores de alguma nova máquina e invenção nas artes." ${ }^{7}$ Esse alvará, inspirado nas leis da Inglaterra e dos Estados Unidos, colocou o Brasil como um dos pioneiros na concessão de patentes em uma época em que sua economia estava fortemente baseada em atividades agrícolas, em especial, na produção e exportação de açúcar, algodão e café. Entretanto, os esparsos registros da época apontam para um pequeno número de privilégios concedidos sob a vigência do alvará, chegando a apenas 26 no total (RODRIGUES, 1973).

6 Segundo Odagiri et al. (2010), os países com lei de patentes em vigor no início do século XIX eram: Inglaterra (com a primeira lei de patentes datada de 1823), Estados Unidos (1790), França (1791), Rússia (1812), Prússia (1815), Bélgica (1817), Países Baixos (1817) e Espanha (1820).

7 O referido Alvará representa a primeira norma legal a conferir direito de propriedade industrial a inventores no Brasil, embora não seja considerado uma lei de patentes. Em seu item VI é estabelecido que: Sendo muito conveniente que os inventores e introdutores de alguma nova máquina, e invenção nas artes, gozem do privilégio exclusivo além do direito que possam ter ao favor pecuniário, que sou servido estabelecer em benefício da indústria e das artes; ordeno que todas as pessoas que estiverem neste caso apresentem o plano do seu novo invento à Real Junta do Comércio; e que esta, reconhecendo a verdade, e fundamento dele, lhes conceda o privilégio exclusivo por quatorze anos, ficando obrigadas a publicá-lo depois, para que no fim desse prazo toda a Nação goze do fruto dessa invenção. Ordeno outrossim, que se faça uma exata revisão dos que se acham atualmente concedidos, fazendo-se público na forma acima determinada, e revogando-se todos os que por falsa alegação, ou sem bem fundadas razões obtiveram semelhantes concessões. 
Com o País já independente, a Constituição de 1824 garantiu aos inventores a propriedade de suas descobertas ou de suas produções. Tal norma constitucional foi regulamentada pela primeira lei de patentes brasileira em 28 de agosto de 1830, curiosamente, anterior à de Portugal, promulgada somente em 1837. Seu objetivo era assegurar a propriedade ao que descobrir, inventar ou melhorar uma indústria útil e um prêmio ao que introduzir uma indústria estrangeira. ${ }^{8}$

A patente era concedida gratuitamente aos inventores e melhoristas que comprovassem por escrito a autoria da invenção. Havia, ainda, a realização de um exame prévio para comprovar a novidade e a utilidade da invenção. Rodrigues (1973), com base nos Relatórios Ministeriais, indica que vários pedidos de patente foram recusados por não cumprirem os requisitos de novidade e utilidade, o que sugere que os exames de mérito da patente foram realizados com algum rigor.

Além disso, a lei adotava a prática da "revelação" da invenção, em que o requerente deveria depositar "no Arquivo Público uma exata e fiel exposição dos meios e processos, de que se serviu, com planos, desenhos ou modelos, que os esclareça, e sem eles, se não puder ilustrar exatamente a matéria" (art. $2^{\circ}$ ). Nesse sistema, a patente era concedida ao "primeiro a inventar" e o inventor perderia a patente caso não colocasse em prática a invenção no prazo de dois anos após a concessão da patente ou se já tivesse obtido patente no exterior pela mesma invenção. Nesse último caso, teria direito apenas ao prêmio por ter sido introdutor.

Percebe-se, portanto, uma preocupação tanto com a transformação da invenção em inovação (já que ela deveria ser introduzida no mercado brasileiro até dois anos após a concessão), quanto com a difusão da inovação, evidenciada pela prática da revelação. Em outras palavras, é possível identificar o desejo do legislador de transformar esses inventos em benefícios para a sociedade, indo além da mera proteção de direitos de propriedade. Infelizmente, não há registros da eficácia desta disposição.

8 A palavra "indústria" foi empregada na lei no sentido de invenção útil. 
Assim como a primeira lei de patentes dos Estados Unidos, a lei brasileira não definiu um prazo único para a validade das patentes. De acordo com a lei, a patente poderia ter a duração de cinco a vinte anos, conforme a qualidade do invento. Vale destacar que o texto do projeto original da lei não mencionou qualidade, mas a "importância e valor da descoberta, introdução ou melhoramento." ${ }^{9}$ Assim, podemos dizer que a duração da patente era, de certa forma, endógena, pois dependia das características da invenção e da discricionariedade do órgão examinador.

Apesar de suas boas intenções, a lei não abordou os obstáculos à atividade inventiva no País e ainda criou uma barreira tecnológica por seu forte requisito de novidade ao não conceder patentes a invenções já patenteadas no exterior. De acordo com Relatórios Ministeriais, apesar da previsão do prêmio monetário aos introdutores de invenções estrangeiras, que deveria ser proporcional à utilidade e à dificuldade da introdução, não houve recursos alocados para esse fim no orçamento, levando à conclusão de que isso possivelmente nunca se concretizou (RODRIGUES, 1973). Além disso, ao desestimular a cópia de invenções estrangeiras, a lei impôs uma barreira tecnológica desnecessária ao Brasil, pois, no século XIX, vários países concediam patentes sem nenhuma prova de originalidade, possibilitando a cópia e a difusão tecnológica (CHANG, 2000).

Essa proibição do registro de patentes já concedidas no exterior começou a ser contestada na década de 1860 . Nas palavras de um ministro "não é justo denegar a patente de invenção, sob o pretexto de ser já conhecida fora do império" (Rodrigues, 1973 p. 656). Assim, de acordo com Cerqueira (1982, p. 10):

Durante a vigência da lei, o prêmio passou a ser substituído por um privilégio de exploração de duração variável, concedido pelo Governo, ad referendum do Poder Legislativo. Tal prática parece ter sido adotada por falta de verba orçamentária destinada aos prêmios instituídos pela lei. Em 1880, por aviso de 7 de abril, o Ministro da Agricultura levou ao conhecimento dos interessados a resolução tomada, de não se concederem mais patentes dessa espécie, não só em obediência ao texto expresso na lei, como, também, porque nenhum mérito havia na introdução de qualquer indústria ou invenção, da-

9 Projeto de Lei apresentado na Sessão de 21 de julho de 1828 pelo Senador Manoel Ferreira da Câmara. Anais do Senado. http://www.senado.leg.br/publicacoes/anais/pdf/Anais Imperio/1828/1828\%20Livro\%202ok.pdf. 
das as maiores facilidades de comunicação, então existentes, com os países estrangeiros, e o grau de civilização que havia atingido o país.

Na década de 1870, a lei sofreu uma modificação importante em sua interpretação ao se excluírem os exames prévios dos pedidos de patentes e se iniciar a concessão de patentes a estrangeiros, como Thomas A. Edison (RODRIGUES, 1973). A alegação para suspensão dos exames prévios foi o reconhecimento dos direitos dos inventores ao pleno segredo de suas descobertas. Durante vários anos, a Sociedade Auxiliadora da Indústria Nacional realizou o exame prévio de diversos pedidos de patentes. Os inventores argumentavam que os funcionários dessa Sociedade - uma instituição fora da administração pública - teriam acesso aos segredos de patentes antes da sua expedição, o que violaria o direito à confidencialidade.

Os descontentamentos com a legislação de patentes arrastaram-se durante duas décadas, culminando na aprovação de uma nova lei de patentes em 1882. A nova lei foi elaborada durante o período das primeiras reuniões que precederam a Convenção de Paris para a Proteção da Propriedade Intelectual, ocorrida em 1883, da qual o Brasil foi um dos signatários, e incorporou os principais princípios da convenção em sua legislação: o priority right ${ }^{10}$ e o tratamento igual a pedidos de patentes de nacionais e estrangeiros.

A nova lei padronizou o prazo de vigência da patente para quinze anos, mas manteve a exigência da exploração da patente para evitar a caducidade, estendendo o prazo para iniciar a atividade industrial de dois para três anos. Outras mudanças importantes foram a concessão de patentes a estrangeiros que já possuíam patentes em outros países e a manutenção do exame prévio minucioso apenas para produtos alimentares, químicos e farmacêuticos, com os demais dispensados desse exame. A mudança institucional representada pela nova lei foi no sentido de facilitar a obtenção de patentes, tanto de brasileiros como de estrangeiros.

${ }^{10}$ Também chamado de prioridade unionista, é um princípio segundo o qual aquele que solicitar uma patente de invenção tem o direito de solicitar a mesma patente em qualquer dos países signatários dentro de um prazo de doze meses, tendo a patente original como base para o início da proteção do direito de propriedade industrial nos demais países. 


\section{A Base de dados}

As informações sobre os privilégios de invenção foram organizadas pela primeira vez por Rodrigues (1973), que realizou uma ampla pesquisa com base nos documentos do Arquivo Nacional e em relatórios ministeriais do Império. O autor coletou e organizou os dados de patentes entre 1830 e 1891. Apesar do grande esforço realizado pelo autor, encontramos diversas falhas em sua lista de patentes. Há uma lacuna da relação das patentes concedidas entre 1840 e 1848. Além disso, as informações de Rodrigues para os primeiros anos de vigência da lei de patentes não correspondem ao número que é informado nos relatórios ministeriais. Outra inconsistência identificada foi a inclusão de privilégios de exploração de minerais, de construção de ferrovias, de navegação a vapor em determinados rios, entre outros, que não correspondem ao critério para a concessão de privilégios de invenção estabelecido pela lei de 1830. Essas falhas, somadas a outras, como informações duplicadas e erros de ortografia, tornam qualquer análise de sua lista de patentes não confiável.

Diante desse problema, reconstruímos a base de dados completamente a partir da fonte primária, ou seja, verificando todos os Decretos originais de cada patente disponíveis na página da internet da Câmara dos Deputados. ${ }^{11}$

As informações apresentadas por Rodrigues (1973) são: nome do proprietário da patente, uma breve descrição da invenção e o ano de concessão. Ao compilar os decretos descobrimos uma informação que estava perdida na literatura: a duração de cada patente concedida. Ademais, foi possível inferir o tipo de cada patente (se era uma invenção, uma melhoria ou a introdução de uma invenção estrangeira).

\footnotetext{
${ }^{11}$ Apesar do grande valor histórico, os Relatórios ministeriais (acessados na página http://www. crl.edu/brazil/ministerial) não são fonte confiável para a contabilização das patentes. Por exemplo, entre 1830 e 1861, os privilégios de invenção estiveram sob responsabilidade do Arquivo Nacional do Ministério dos Negócios do Império e entre 1862 e 1892 passaram para a Secretaria de Estado dos Negócios da Agricultura, Comércio e Obras. Nessa passagem de responsabilidade, cremos ter havido uma contabilização equivocada do número de privilégios de invenção concedidos no período entre 1830 e 1861, surgindo contradições entre os relatórios dos ministros. Os decretos foram acessados no Portal da Coleção das Leis do Império do Brasil http://www2.camara.leg.br/atividade-legislativa/legislacao/publicacoes/ doimperio. Uma lista completa das patentes está disponível em: http://wwwl2.senado.leg. br/publicacoes/estudos-legislativos/tipos-de-estudos/textos-para-discussao/TD192
} 
As patentes históricas constituem uma valiosa fonte de informação para o estudo de diversos aspectos ligados à atividade inventiva durante quase todo o período imperial. Além dos aspectos econômicos, os dados das patentes de invenção do período permitem avaliar as tendências relativas à urbanização, introdução de novas tecnologias de comunicação e transporte, tecnologias poupadoras de mão de obra, entre outros. Ao todo, foram concedidas 783 patentes no Brasil entre 1830 e 1882, durante a vigência da primeira lei de patentes. São 106 patentes a mais do que a lista de Rodrigues (1973) para o mesmo período.

Para dar uma dimensão da quantidade de patentes concedidas no Brasil, comparamos com outros países com dados disponíveis para o final do século XIX. A mais ampla base de dados históricos de patentes para vários países é a da World Intelletcual Property Organization (WIPO), com informações disponíveis a partir de 1883, ano em que já vigorava uma nova lei de patentes no Brasil. A tabela abaixo apresenta o percentual de patentes de países selecionados em relação ao total de patentes concedidas nos Estados Unidos em 1883. Para o Brasil, computamos a média dos últimos três anos de vigência da primeira lei de patentes (1880-1882).

Tabela 1 - Patentes concedidas em 1883 e percentual em relação ao número de patentes concedidas nos Estados Unidos - Países selecionados

\begin{tabular}{lcc}
\hline País & Patentes concedidas & $(\%)$ em relação aos Estados Unidos \\
\hline Argentina & 59 & 0,28 \\
México & 66 & 0,31 \\
Brasil (a) & 75 & 0,35 \\
Portugal & 78 & 0,37 \\
Reino Unido & 3.962 & 18,72 \\
Estados Unidos & 21.162 & 100 \\
\hline
\end{tabular}

Fonte: World Intellectual Property Organization. (a) Para o Brasil foi calculada a média de patentes concedidas entre 1880 e 1882. Em 1883, sob a vigência de uma nova lei de patentes, foram concedidas 109 patentes no Brasil, o que resulta em 0,52\% em relação aos Estados Unidos.

Os dados mostram que a atividade inventiva no Brasil, em termos de número total de patentes, era próxima a de Portugal. Esse dado, de certa forma, é surpreendente para um país com uma economia agroexportadora sem instituições de ensino superior relevantes, poucas cidades e baseada no trabalho escravo. 


\section{Análise}

A atividade de patenteamento no Brasil teve um início lento, com poucas patentes concedidas nos primeiros trinta anos de vigência da lei. A situação reverteu-se no final do período, com quase $80 \%$ das patentes concedidas após 1870 (ver Figura 1). Nesse mesmo período, a economia brasileira passou por mudanças significativas. Além de ser o momento histórico identificado por pesquisadores como o início da industrialização brasileira (SUZIGAN, 2000), a economia começava a sair de um longo período de estagnação, passando a ter um crescente superávit em seu balanço de pagamentos após décadas de déficits, e a construção de ferrovias disparava, aumentando sua extensão de 869 km em 1871 para 4.467 km em 1882.

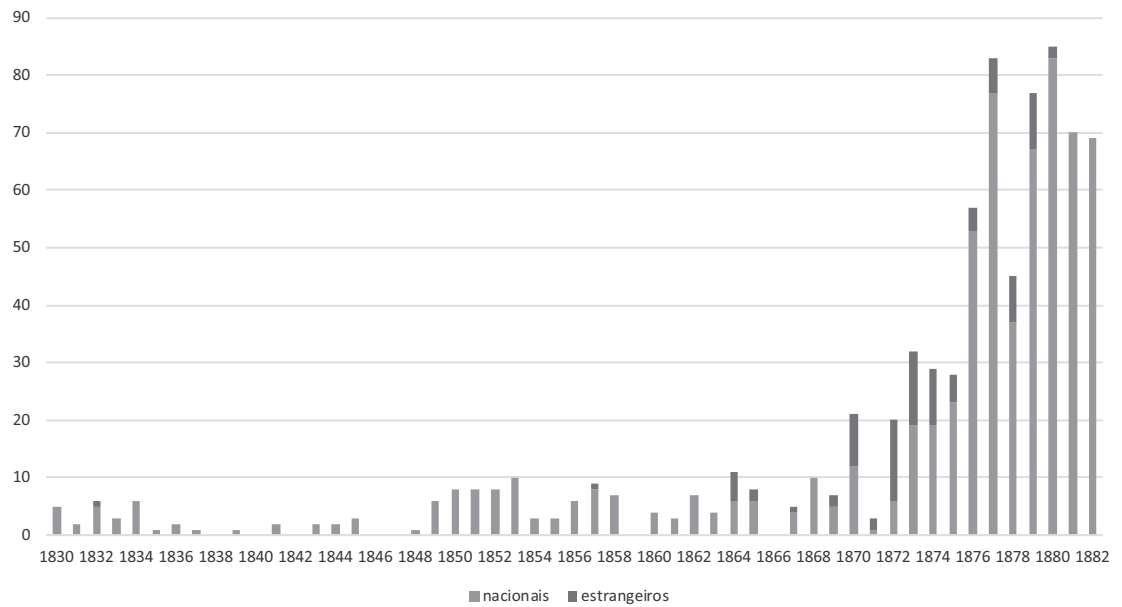

Figura 1 - Evolução de patentes no Brasil (1830-1882)

Fonte: Elaboração própria.

O desempenho da economia atraiu diversas empresas estrangeiras. ${ }^{12}$ Como consequência, cresceu também o interesse de estrangeiros em proteger suas invenções no Brasil. No início da década de 1870, o número de patentes concedidas a estrangeiros chegou a superar o de patentes concedidas a nacionais.

\footnotetext{
${ }^{12}$ Por exemplo, diversos Decretos de 1872 concediam a companhias inglesas a necessária autorização para funcionar no Império, como: The South Brasilian Railway Limited, The Amason Steam Navigation Company Limited, S. Paulo Gas Company, e The Madeira and Mamore Railway Company.
} 
Nas subseções seguintes, analisamos a conexão entre as invenções e a estrutura econômica do País, bem como os efeitos da lei sobre a atividade inventiva.

\subsection{Conexão das patentes com a estrutura produtiva}

Para analisar a relação entre a atividade inventiva e as transformações econômicas e sociais em curso no Brasil no século XIX, classificamos as patentes de acordo com o seu uso principal. Griliches (1990) discute os problemas de se classificar patentes por setores econômicos, dado que uma invenção pode ter uso simultâneo em diversos ramos da economia, sendo difícil determinar em certos casos qual o setor mais beneficiado pela invenção. Ademais, uma invenção pode ser tanto insumo de um setor como produto de outro. Essa tarefa é ainda mais desafiadora quando lidamos com descrições de patentes históricas, muitas vezes imprecisas, podendo levar a enganos quanto à natureza do produto ou do processo em questão. Por exemplo, uma invenção pode ser classificada de acordo com o setor industrial com maior probabilidade de tê-la produzido ou com o setor que usará o produto final resultante da invenção, dependendo da questão a ser estudada.

Dado que estamos interessados na importância socioeconômica das invenções, classificamos as patentes de acordo com o setor de uso das invenções, baseando-nos em suas descrições. Por exemplo, uma invenção descrita como "máquina para descascar café" foi classificada no setor agrícola, no subsetor café, e no grupo equipamento. As categorias foram escolhidas de acordo com a estrutura econômica brasileira na segunda metade do século XIX. Como qualquer classificação subjetiva, a nossa está sujeita a imprecisões, o que representa uma das limitações da análise.

A Tabela 2 mostra o número de patentes de acordo com setor e subsetor. As patentes relacionadas à agricultura prevalecem, representando $29,9 \%$ do total. O café destaca-se como o mais importante subsetor. Das 783 patentes, 141 (18\%) são relacionadas diretamente à atividade cafeicultora. Esse número mostra que havia uma estreita conexão entre a atividade inventiva e a atividade econômica. Ao longo do século XIX, o café se tornou a principal commodity no balanço de pagamentos brasileiro. Por exemplo, em 1891, o café representava 
63\% das exportações brasileiras (BAER, 2001). Entretanto, não é possível estimar o efeito das invenções na produção de café.

Tabela 2 - Patentes classificadas de acordo com setor e subsetor de aplicação

\begin{tabular}{l|c|c|c}
\hline Setor & Subsetor & Patentes & $(\%)$ \\
\hline Agricultura & Café & 141 & 18 \\
& Açúcar & 36 & 4,6 \\
& Outros & 57 & 7,3 \\
Transporte & Total & 234 & $\mathbf{2 9 , 9}$ \\
& Carga & 20 & 2,6 \\
& Urbano & 15 & 1,9 \\
& Comunicações & 4 & 0,5 \\
Bens de Consumo & Geral & 83 & 10,6 \\
& Total & 122 & 15,6 \\
& Alimentos & 46 & 5,9 \\
Extrativista & Têxtil & 15 & 1,9 \\
Outros & Outros & 54 & 6,9 \\
Total geral & Total & 115 & 14,7 \\
\hline
\end{tabular}

Fonte: Elaboração própria.

O número de patentes relacionadas à produção de café pode ser muito maior, já que a subcategoria "outros" em agricultura foi criada principalmente para patentes cuja descrição não especificava sua aplicação ou sua descrição era geral demais para ser aplicável a muitas culturas. Essa categoria engloba 57 patentes (7,3\% do total). Já as patentes relacionadas ao açúcar representam um valor mais modesto $(4,6 \%$ do total). Outra distinção foi feita entre invenções relacionadas a equipamentos e a lavoura (não descrita na tabela) e aplicada às três categorias agrícolas mencionadas. Ao todo, foram classificadas 210 patentes (quase $27 \%$ do total) como equipamentos e 24 (3\% do total) como de lavoura, tais como invenções destinadas a exterminar formigas.

Devido à relevância da produção de café para a economia brasileira no período coberto pela base de dados, analisamos sua dinâmica tecnológica. Inicialmente, destacamos que 98,5\% das patentes diretamente relacionadas ao café referiam-se a máquinas e equipamentos para aplicação pós-colheita dos grãos. Entre eles, havia aparelhos para limpar os grãos, remover a polpa, descascar, secar e encerar. Também 
foram patenteados métodos de armazenamento para a manutenção dos grãos antes da exportação.

Em segundo lugar, a produção de café era intensiva em trabalho e esse fator de produção estava encarecendo. Pressionado pela Inglaterra, o Brasil proibiu o tráfico de escravos em 1850. Apesar dessa proibição, o mercado doméstico de escravos continuou ativo até a abolição em 1888. Na década de 1860, os impactos da restrição da oferta de escravos e, talvez mais importante, do aumento da demanda por mão de obra, passaram a pressionar os preços dos escravos na região cafeicultora. Os valores aumentaram em média $10 \%$ ao ano nessa década (VERSIANI et al. 2003).

Essa mudança institucional e estrutural no mercado de trabalho teve impacto na adoção de novas tecnologias. Acemoglu (2010) argumenta que uma restrição de trabalho pode induzir avanços tecnológicos quando as invenções são poupadoras de mão de obra. No caso brasileiro, o número de máquinas agrícolas anunciadas por importadores em jornais e notícias de invenções locais aumentaram de forma considerável na década de 1860 (CANABRAVA, 2005). Nossos dados sustentam o argumento de Acemoglu (2010), uma vez que a maior parte das patentes de café foi concedida após 1860 .

Devido ao intenso crescimento da produção de café na segunda metade do século XIX, o transporte da produção tornou-se crucial. Em nossa classificação de patentes, o segundo setor mais importante é o de transportes $(15,6 \%$ do total). Dividimos esse setor em quatro subsetores (carga, urbano, comunicações e geral). A categoria "carga' contém somente patentes que descrevem algum equipamento ou método de transporte de cargas $(2,6 \%)$. Nessa categoria podem estar pequenos veículos que não eram usados para transporte de grandes cargas, pois a classificação dependeu do que se pôde inferir da descrição dada pelo inventor. A categoria "urbano" $(1,9 \%)$ inclui transporte público, como bondes e trens, além de métodos de coleta de pagamento e contagem de passageiros destinados a evitar fraudes. ${ }^{13}$ A categoria "geral" inclui invenções relacionadas a veículos sem

13 É interessante notar que o serviço de transporte em bondes foi iniciado no Rio de Janeiro em 1868 e, entre 1876 e 1879, foram concedidas oito patentes relacionadas à contagem de passageiros usuários de bondes e trens urbanos. Um exemplo é o Decreto no 6.606, de 1877, que concedeu uma patente pelo prazo de cinco anos para um "aparelho denominado 'Registrador' para indicar o número de passageiros que transitam nos carros das linhas férreas urbanas”. Essa é um exemplo de como os dados históricos de patentes também podem contribuir para o estudo de eventos históricos em outras áreas além da economia. 
uma descrição específica, como eixo de rodas e outros, totalizando $10,6 \%$. Também incluímos nesse setor quatro invenções relacionadas a comunicações.

Uma subdivisão também foi aplicada para analisar o impacto da introdução e expansão das ferrovias na atividade inventiva e para distinguir pequenos veículos, como carruagens, de trens e navios (não descrita na tabela). Das patentes de transporte, 33 (4\% do total) são claramente relacionadas a ferrovias e $9 \%$ das patentes são relacionadas a pequenos veículos.

As patentes ligadas aos bens de consumo representam $14,7 \%$ do total. No período analisado, o Brasil ainda importava uma grande variedade de bens de consumo. Contudo, a instabilidade da taxa de câmbio passou a fornecer um incentivo a investimentos industriais para substituir importações (VERSIANI, 1980). Casas importadoras passaram a adquirir equipamentos estrangeiros e a produzir tecidos como forma de se proteger das flutuações cambiais.

Ao mesmo tempo, o mercado doméstico entre as províncias de diferentes regiões tornava-se cada vez mais relevante. Marcondes (2012) analisa a importância da navegação de cabotagem para o comércio e o consumo interno e a parcela de consumo interprovincial no século XIX. Essa perspectiva nos permite compreender o tipo de mercado existente nessa economia e explicar o interesse de inventores em certos setores. $\mathrm{O}$ autor mostra que o açúcar e o café, além da importância para o mercado exportador, também tinham um papel relevante na economia doméstica. Como exemplo, cita que entre 1869 e 1873, açúcar e seus derivados, carne, couros e tabaco constituíram 44,8\% do total de commodities negociadas no comércio interprovincial.

Para avaliar as patentes relacionadas aos bens de consumo, dividimos o setor em três subsetores: alimentos $(5,9 \%$ do total de patentes), têxtil $(1,9 \%)$ e outros $(6,9 \%)$. Essas categorias representam também os primeiros setores nos quais o Brasil começou a esboçar um esforço industrial. Suzigan (2000) analisa dados históricos sobre maquinário têxtil importado da Inglaterra que sustentam a tese de que a industrialização brasileira se iniciou por volta de 1870 . De acordo com Cruz e Tavares (1986), o número de inventores relacionados com o setor têxtil começou a crescer após 1877, e em 1891 já havia 61 patentes relacionadas a essa indústria. Como nossa base de dados 
apresenta informações apenas até o ano de 1882, não foi possível capturar esse importante aspecto da industrialização brasileira.

O setor extrativista $(4,5 \%$ do total de patentes) inclui, principalmente, a mineração (ouro e diamantes) e a pesca. A categoria "outros" inclui invenções tais como motores em geral, vidros, cimento, máquinas para corte de pedras, métodos para produção de tijolos, além de invenções cuja descrição era demasiadamente vaga para permitir sua inserção em uma das categorias acima.

Em suma, pelo menos um terço da atividade inventiva no Brasil durante o período entre 1830 e 1882 esteve relacionada ao complexo agroexportador (agricultura e transporte de cargas). A análise acima contribui para validar a tese de Cruz e Tavares (1986) de que a atividade inventiva durante o século XIX pode ser explicada pela lógica da demanda (demand pull). Não havia atividade científica relevante no País e nenhum desenvolvimento de tecnologias de propósito geral, como eletricidade, para iniciar um movimento de "onda de invenções" do tipo technology push. O que havia era uma população crescente demandando bens de consumo simples, um setor exportador em expansão buscando novos métodos de transporte e desafios técnicos de construção de ferrovias a serem resolvidos de modo a conectar novas e produtivas fazendas a quilômetros de distância dos principais portos. Havia também grande demanda para novos métodos de processamento e secagem de grãos de café. Isso era importante não só pela restrição de mão de obra, mas porque aumentava o valor dos grãos em torno de $10 \%$ e possibilitava o uso de terras distantes para produzir café e transportar para portos sem que a produção apodrecesse (SILVA, 1986).

Da evolução geral das patentes e de sua conexão com a atividade econômica, observamos que número de patentes só começou a crescer quando a economia brasileira passou por grandes mudanças que levaram ao seu desenvolvimento. Assim, a lei de patentes de 1830 representou um mecanismo de estímulo à atividade inventiva limitado pelas circunstâncias de estagnação de parte do período analisado. 


\subsection{Duração e amplitude das patentes}

Nesta subseção, analisamos a duração das patentes e inferimos sua amplitude de modo a avaliar aspectos específicos da eficiência da lei de patentes. Inicialmente, destacamos que a Lei de 1830 permitia prazos distintos para cada patente de acordo com a qualidade de cada invenção, o que é, segundo Nordhaus (1972) e Scherer (1972), característica de um sistema ideal de patentes. Apesar de ser praticamente impossível saber a metodologia e os critérios utilizados pelos avaliadores das patentes no século XIX, e de ser provável que, na existência de tais critérios, os mesmos possam ter sido alterados ao longo do tempo, é relevante destacar que a primeira lei de patentes brasileira adotava um critério de determinação da duração da patente próximo ao ótimo.

A duração de cada patente concedida permite inferir a importância dada pelos responsáveis pelo exame das patentes a cada invenção. Com isso, é possível contornar um dos grandes problemas relacionados ao uso de patentes como indicadores econômicos destacado por Griliches (1990). Segundo o autor, muitas patentes possuem pequeno valor econômico por refletirem aprimoramentos marginais. Por outro lado, existem patentes de invenções de grande valor. Contudo, é extremante difícil distinguir entre esses dois extremos, por não haver um método para ponderar a importância de cada patente. A lei de 1830 permitiu essa ponderação por meio da duração variável para as patentes de acordo com a qualidade de cada invenção.

A Tabela 3 mostra a duração das patentes pelo tipo de privilégio de invenção. ${ }^{14}$ A média foi de 9,2 anos, com pequenas diferenças entre os tipos. Novas invenções (quase $80 \%$ do total) foram concedidas com a menor duração média $(9,0$ anos) enquanto as invenções estrangeiras $(12,1 \%)$ duraram uma média de 9,5 anos. Essa maior "importância" dada às invenções estrangeiras era esperada. Devido às dificuldades de comunicações no século XIX, inventores estrangeiros só estariam interessados em proteger em outros países as invenções mais relevantes.

${ }^{14}$ Com base na descrição da invenção, cada patente foi classificada em invenção (art. $1^{\circ}$ da Lei de 1830), melhoramento (art. $2^{\circ}$ ) ou introdução de invenção estrangeira no país (art. $3^{\circ}$ ), já que essas começaram a ser permitidas em 1870, como discutido na terceira seção. 
Os melhoramentos representaram $8,9 \%$ do total de patentes, mas, curiosamente, são o tipo de patente com a maior duração média $(9,8$ anos). Nossa hipótese para explicar esse fato é que somente invenções com importância social ou econômica (que já possuíam uma duração maior) tornavam-se objeto de melhoramentos, que acabavam tendo uma duração semelhante à da invenção original.

Tabela 3 - Duração média das patentes de acordo com o tipo de privilégio (18301882)

\begin{tabular}{lcccccc}
\hline Tipo de Privilégio & Patentes & $(\%)$ & $\begin{array}{c}\text { Duração } \\
\text { Média em } \\
\text { anos }\end{array}$ & $\begin{array}{c}\text { Desvio } \\
\text { Padrão }\end{array}$ & Min & Max \\
\hline \hline Invenções & 618 & 78,9 & 9 & 3 & 4 & 20 \\
Melhorias & 70 & 8,9 & 9,8 & 3,5 & 4 & $24^{\text {a }}$ \\
Invenções Estrangeiras & 95 & 12,1 & 9,5 & 3 & 5 & 20 \\
\hline Total & 783 & 100 & 9,2 & 3,1 & 4 & 24 \\
\hline
\end{tabular}

Fonte: Elaboração própria. (a): A patente referente ao Decreto n ${ }^{\circ} 753$, de 1850, para "melhoramentos no fabrico de velas estearinas" foi concedida incialmente por 14 anos, sendo estendida por mais 5 anos em 1868 e por mais 5 em 1872.

Com relação à duração por setor da economia, as patentes relacionadas a transportes tiveram duração média de 9,4 anos, a maior entre os setores classificados. Patentes dos setores de bens de consumo, extrativista e agrícola duraram 9,2 anos. Entretanto, as médias não são estatisticamente diferentes. Mesmo quando desagregamos os dados para subsetores (comparando patentes relacionadas ao café e açúcar; a transporte de carga e transporte urbano, alimentos e têxtil) e grupos (equipamentos e ferrovias) não é possível afirmar que algum determinado grupo de invenções teve duração média estatisticamente superior. Individualmente, um examinador de patente pode ter considerado uma patente ligada a ferrovias mais importante que a de um equipamento para despolpar café, concedendo-lhe mais anos de duração. Contudo, não é possível afirmar que invenções relacionadas a um setor (ou subsetor) sejam mais importantes que as demais com base na classificação proposta.

A distribuição da duração das patentes alterou-se ao longo das décadas (Figura 2). A participação relativa de patentes mais duradouras caiu de forma constante ao longo do tempo. É possível que, no início, as invenções fossem tão raras que para um terço das patentes foi concedida duração de quinze anos ou mais. Patentes de oito anos de 
duração aparecem em maior quantidade somente na década de 1870, sendo a maior parte associada às invenções estrangeiras. Isso sugere que os examinadores de patentes concediam oito anos de proteção a qualquer patente estrangeira como "regra de bolso". Em todas as décadas, a moda foi de dez anos.

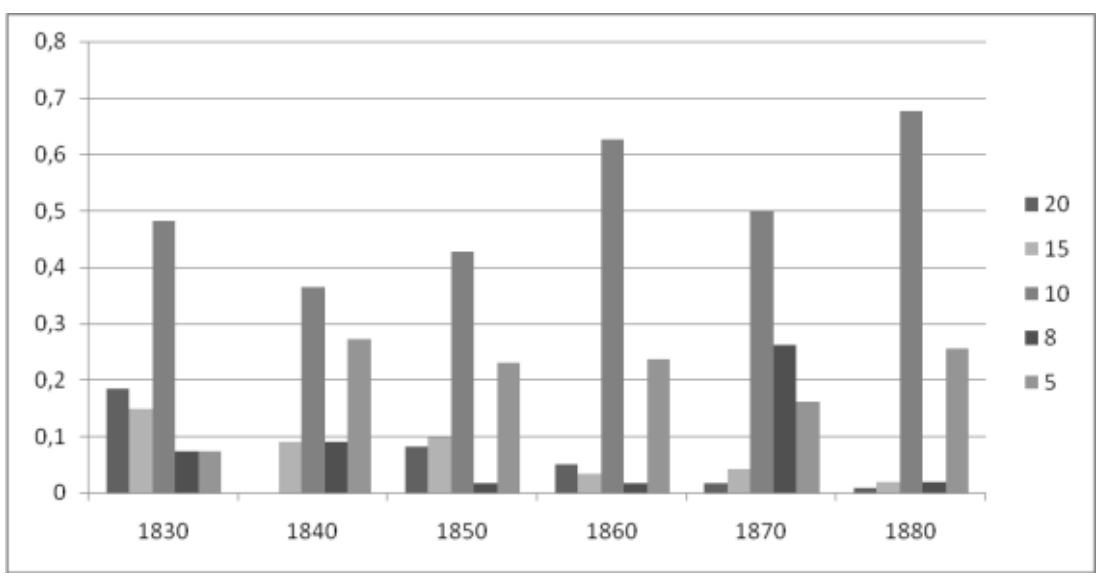

Figura 2 - Duração ao longo do tempo

Fonte: Elaboração própria.

A análise da amplitude das patentes foi feita a partir de sua descrição, sendo limitada pela disponibilidade de informações. O texto da lei de 1830 sugere que as patentes concedidas eram estreitas ao assegurar propriedade industrial para melhoramentos. $\mathrm{O}$ art. $2^{\circ}$ da Lei dispõe que "o que melhorar uma descoberta, ou invenção, tem no melhoramento o direito de descobridor, ou inventor".

Para verificar a amplitude das patentes, nos concentramos naquelas relacionadas à atividade cafeicultora. Inicialmente, destacamos o considerável número de invenções similares (de acordo com a descrição fornecida). Várias patentes foram concedidas para invenções destinadas ao mesmo estágio de produção. Por exemplo, 30 patentes foram concedidas para máquinas de processamento em geral, 23 para máquinas de polimento, 21 para máquinas de secagem e 11 para a remoção da casca. 
Esse fato sugere que, pelo menos para as invenções relacionadas à produção de café, o primeiro sistema de patentes brasileiro pode ser caracterizado como estreito, no sentido de que a patente era concedida apenas para invenções muito específicas. Assim, era possível inventar equipamentos similares sem infringir outra patente.

Portanto, o primeiro sistema de patentes brasileiro conferiu direito de propriedade restrito ao inventor, permitindo o surgimento de produtos similares e maior competição, e de duração variável. Tal combinação de características não é apontada em nenhum dos estudos destacados na literatura como sendo uma combinação eficiente. Klemperer (1990), por exemplo, argumenta que patentes estreitas deveriam ser acompanhadas de duração infinita.

\subsection{Patentes de estrangeiros}

$\mathrm{O}$ art. $3^{\circ}$ da Lei de 1830 dispõe que "ao introdutor de uma indústria estrangeira se dará um prêmio proporcionado à utilidade, e dificuldade da introdução". Essa regra revelou-se completamente ineficaz diante da ausência de recursos orçamentários para custear o referido prêmio. Segundo relatos de ministros, nunca houve o pagamento desse prêmio. Havia um consenso na época de que a aplicação desse dispositivo estaria privando o País de atrair novas tecnologias. Sendo assim, a partir da década de 1860, passou-se a conceder "privilégio de introdução" aos inventores estrangeiros com status de "privilégio de invenção", o que durou até 1880, resultando em 95 privilégios de introdução.

A Tabela 4 mostra a importância atribuída às invenções estrangeiras e aos melhoramentos por setor. O primeiro aspecto considerado é a predominância de invenções locais (e melhoramentos) relacionadas ao setor agrícola. Em outras palavras, o setor dinâmico da economia fornecia desafios tecnológicos e os inventores brasileiros lidavam com esses desafios resolvendo problemas de restrição de mão de obra e melhorias de qualidade no processamento de grãos de café. A proporção de invenções estrangeiras mostrou-se relevante somente nos setores de transportes $(12,3 \%)$ e de bens de consumo $(15,7 \%)$. 
Tabela 4 - Patentes por setor e tipos de privilégios (\%)

\begin{tabular}{lcccc}
\hline Setor & Invenções & Melhorias & Invenções Estrangeiras & Total \\
\hline Agricultura & 82,5 & 13,2 & 4,3 & 100 \\
Transporte & 82 & 5,7 & 12,3 & 100 \\
Bens de Consumo & 79,1 & 5,2 & 15,7 & 100 \\
Extrativista & 74,3 & 17,1 & 8,6 & 100 \\
Outros & 75,1 & 7,2 & 17,7 & 100 \\
Total & 78,9 & 8,9 & 12,1 & 100 \\
\hline
\end{tabular}

Fonte: Elaboração própria.

\section{Conclusão}

Neste trabalho apresentamos uma análise econômica da primeira lei de patentes brasileira, que vigorou entre 1830 e 1882. O propósito da lei era estimular a geração de invenções. Nossos resultados mostram que a lei de 1830 pode ser considerada eficiente, dado que as alternativas para estimular invenções exigiriam mais recursos. Durante todo o período de vigência da lei, nunca houve orçamento para pagar prêmios aos inventores estrangeiros previstos na lei. A limitação orçamentária do período imperial também impossibilitou o incentivo à pesquisa básica e acadêmica. Assim, a instituição de uma lei de patentes foi o mecanismo menos dispendioso possível para incentivar as invenções no Brasil do século XIX.

Durante as três primeiras décadas, o número de patentes foi baixo, o que levou analistas e ministros da época a acharem que a culpa era da legislação, que concedia prazo muito curto e não permitia patentes de invenções estrangeiras. Entretanto, nossa análise mostra que a atividade de patenteamento só começou a se tornar mais relevante quando a economia brasileira passou por mudanças após a década de 1870, como o início da industrialização, a expansão da cultura do café e a escassez de mão de obra. Assim, apesar de existir uma lei para incentivar as invenções, o maior estímulo veio do crescimento da economia, o que está de acordo com Schmookler (1966) e Acemoglu e Linn (2004), que apresentam evidências de que o número de invenções é determinado pelo tamanho do mercado. 
Os resultados indicam que a escassez de mão de obra também teve efeitos sobre a atividade inventiva do período. As patentes relacionadas ao beneficiamento do café representaram praticamente $20 \%$ de todas as 783 patentes do período, e tinham um caráter de serem poupadoras de mão de obra.

Podemos dizer que durante a vigência da lei de patentes de 1830, a atividade inventiva esteve bastante conectada com a estrutura econômica e social do País. Os resultados reforçam a hipótese de Acemoglu (2010) de que a escassez de mão de obra induz o surgimento de invenções poupadoras desse fator de produção. Ademais, estão de acordo com a conclusão de Cruz e Tavares (1986), sobre as patentes brasileiras do século XIX, de que as invenções respondiam a estímulos da demanda.

A aplicação da lei resultou em um sistema que concedeu patentes estreitas e de duração variável. Embora as patentes tenham sido concedidas com períodos distintos de duração de acordo com a qualidade de cada invenção, não encontramos evidência de padrões diferenciados de duração por setores da economia. Assim, patentes relacionadas à agricultura duravam, em média, o mesmo tempo que patentes de bens de consumo, ou seja, 9,2 anos.

Nossa análise mostra que pouco resultado surge quando se institui uma lei de patentes em um ambiente econômico de estagnação. $\mathrm{O}$ número de patentes apenas começou a se elevar quando as condições econômicas melhoraram. Ademais, a experiência única de se determinar prazos distintos para cada invenção não teve efeitos relevantes para a atividade inventiva no Brasil. 


\section{Referências}

ACEMOGLU, Daron. When does labor scarcity encourage Innovation? Journal of Political Economy, v. 118, n. 6, p. 1037-78, 2010.

ACEMOGLU, Daron; LINN, Joshua. Market Size in Innovation: Theory and Evidence from the Pharmaceutical Industry. The Quarterly Journal of Economics, vol. 119 (3), p.1049-1090, August, 2004.

BAER, Werner. The Brazilian Economy: Growth and Development. Praeger, 2001.

BOLDRIN, Michele; LEVINE, David. The Case against Patents. Journal of Economic Perspectives, 27(1), p. 3-22, 2013.

CANABRAVA, Alice P. História Econômica: Estudos e Pesquisas. Editora UNESP, 2005.

CERQUEIRA, João da Gama. Tratado da Propriedade Industrial. Vol 1. Editora Revista dos Tribunais, São Paulo, 1982.

CHANG, Ha-Joon. Kicking Away the Ladder: Development Strategy in Historical Perspective. Anthem Press, 2002.

CRUZ, Helio; TAVARES, Martus. As Patentes Brasileiras de 1830 a 1891. Estudos Econômicos 16, no. 2 p. 205-25, 1986.

DENICOLÒ, Vincenzo. Patent Races and Optimal Patent Breadth and Length. The Journal of Industrial Economics, Vol. 44, No. 3, p. 249-265, 1996.

GALLINI, Nancy. Patent policy and costly imitation. The RAND Journal of Economics, p. 52-63, 1992.

GILBERT, Richard; SHAPIRO, Carl. Patent Length and Breadth. RAND Journal of Economics, 21, no. 1, p. 106-12, 1990.

GOLDIN, Claudia. Cliometrics and the Nobel. Journal of Economic Perspectives. V. 9 no. 2, p. 191208, 1995.

GRILICHES, Zvi. Patent statistics as economic indicators: a survey. Journal of Economic Literature 28, p. 1661-797, 1990.

KLEMPERER, Paul. How broad should the scope of patent protection be? RAND Journal of Economics v. 21, no. 1.p 113-30, 1990.

LANGINIER, Corinne; MOSCHINI, GianCarlo. The Economics of Patents: An Overview. CARD Working Papers. Paper 335, 2002.

MACHLUP, Fritz; PENROSE, Edith. The Patent Controversy in the Nineteenth Century. The Journal of Economic History v. 10, no. 1, p. 1-29, 1950.

MARCONDES, Renato. O Mercado Brasileiro no Século XIX: Uma Visão Por Meio do Comércio de Cabotagem. Revista de Economia Politica v. 32, no. 1,p. 142-66, 2012.

MAZZOLENI, Roberto; NELSON, Richard. (1998) Economic theories about the benefits and costs of patents. Journal of Economic Issues; v. 32, n. 4, 1998.

MOKYR, Joel. Intellectual Property Rights, the Industrial Revolution, and the Beginnings of Modern Economic Growth. American Economic Review, v. 99 (2), p. 349-55, 2009.

MOSER, Petra. How Do Patent Laws Influence Innovation? American Economic Review, 94(4), p. 1214-36, 2005.

MOSER, Petra. Why Don't Inventors Patent? National Bureau of Economic Research Working Paper 13294, 2007.

NORDHAUS, William. Invention, growth and welfare, Cambridge, Mass., MIT Press, 1969.

NORDHAUS, William. The Optimum Life of a Patent: Reply. The American Economic Review, Vol. 62, No. 3, pp. 428-431, 1972. 
ODAGIRI, Hiroyuki; GOTO, Akira; SUNAMI, Atsushi; NELSON, Richard. (Org.). Intellectual Property Rights, Development, and Catch-Up: An International Comparative Study. Oxford: Oxford University Press, 2010.

O’DONOGHUE; Ted; SCOTCHMER, Suzanne; THISSE, Jacques-François. Patent Breadth, Patent Life, and the Pace of Technological Progress. Journal of Economics \& Management Strategy, V. 7, Issue 1, p.1-32, Spring, 1998.

RODRIGUES, Clovis. Inventiva Brasileira, Brasília: Instituto Nacional do Livro, 1973.

SCHERER, Frederic. Nordhaus' Theory of Optimal Patent Life: A Geometric Reinterpretation. The American Economic Review. Vol. 62, No. 3 (Jun., 1972), pp. 422-427, 1972.

SCHMOOKLER, Jacob. Invention and Economic Growth. University Press, 1966.

SILVA, Sergio. Expansão Cafeeira e Origens da Indústria no Brasil. Ed. Alfa-Omega, 1986.

STIGLITZ, Joseph. Economic foundations of intellectual property rights. Duke Law Journal. Vol. 57: 1693, 2008.

STIGLER, George. Law or Economics? The Journal of Law \& Economics Vol. 35, No. 2, pp. 455-468, 1992.

SUZIGAN, Wilson. Indústria Brasileira; Origem e Desenvolvimento. São Paulo, Hucitec, 2000.

VERSIANI, Flávio. Industrial Investment in an 'Export' Economy: The Brazilian Experience Before 1914. Journal of Development Economics 7, no.3, p. 307-29, 1980.

VERSIANI, Flavio, TANNURI-PIANTO, Maria; VERGOLINO, José. Demand Factors in the Nineteenth-Century Brazilian Slave Market. Proceedings of the 31th Brazilian Economics Meeting, 2003. 